\title{
Is I-FABP not only a marker for the detection abdominal injury but also of hemorrhagic shock in severely injured trauma patients?
}

Maika Voth*, Thomas Lustenberger, Borna Relja and Ingo Marzi

\begin{abstract}
Background: Hemorrhagic shock can lead to intestinal damage with subsequent hyperinflammation and multiple organ dysfunction syndrome (MODS). The intestinal fatty acid-binding protein (I-FABP) is solely expressed in the intestine and is released extracellulary after tissue damage. This study evaluates the validity of I-FABP as an early biomarker to detect hemorrhagic shock and abdominal injury.

Patients and methods: Severely injured patients with an Injury Severity Score (ISS) $\geq 16$ points and an age $\geq 18$ years, admitted from January 2010 to December 2016, were included. Overall, 26 patients retrospectively presented with hemorrhagic shock to the emergency room (ER): 8 patients without abdominal injury ("HS noAbd") and 18 patients with abdominal injury ("HS Abd"). Furthermore, 16 severely injured patients without hemorrhagic shock and without abdominal injury ("noHS noAbd") were retrospectively selected as controls. Plasma I-FABP levels were measured at admission to the ER and up to 3 days posttraumatic (d1-d3).

Results: Median I-FABP levels were significantly higher in the "HS Abd" group compared with the "HS noAbd" group $(28,637.0 \mathrm{pg} / \mathrm{ml}[\mathrm{IQR}=6372.4-55,550.0]$ vs. $7292.3 \mathrm{pg} / \mathrm{ml}[\mathrm{IQR}=1282.5-11,159.5], p<0.05)$. Furthermore, I-FABP levels of both hemorrhagic shock groups were significantly higher compared with the "noHS noAbd" group (844.4 $\mathrm{pg} / \mathrm{ml}[\mathrm{IQR}=530.0-1432.9], p<0.05)$. The time course of I-FABP levels showed a peak on the day of admission with a subsequent decline in the post-traumatic course. Furthermore, significant correlations between I-FABP levels and clinical parameters of hemorrhagic shock, such as hemoglobin, lactate value, systolic blood pressure (SBP), and shock index, were found.

The optimal cut-off level of I-FABP for detection of hemorrhagic shock was $1761.9 \mathrm{pg} / \mathrm{ml}$ with a sensitivity of $85 \%$ and a specificity of $81 \%$.

Conclusion: This study confirmed our previous observation that I-FABP might be used as a suitable early biomarker for the detection of abdominal injuries in general. In addition, I-FABP may also be a useful and a promising parameter in the diagnosis of hemorrhagic shock, because of reflecting low intestinal perfusion.
\end{abstract}

Keywords: I-FABP, Hemorrhagic shock, Emergency, Abdominal trauma, Biomarker

\footnotetext{
* Correspondence: maika.voth@kgu.de

Department of Trauma, Hand and Reconstructive Surgery, University Hospital,

Goethe University Frankfurt, Theodor-Stern-Kai 7, D-60590 Frankfurt, Main,

Germany
}

(c) The Author(s). 2019 Open Access This article is distributed under the terms of the Creative Commons Attribution 4.0 International License (http://creativecommons.org/licenses/by/4.0/), which permits unrestricted use, distribution, and reproduction in any medium, provided you give appropriate credit to the original author(s) and the source, provide a link to the Creative Commons license, and indicate if changes were made. The Creative Commons Public Domain Dedication waiver (http://creativecommons.org/publicdomain/zero/1.0/) applies to the data made available in this article, unless otherwise stated. 


\section{Introduction}

In severely injured trauma patients, traumatic brain injury and uncontrolled bleeding remain the main causes for early mortality within the first $24 \mathrm{~h}$ after trauma [1].

Hemorrhagic shock results in a circulatory dysfunction causing decreased tissue oxygenation and an accumulation of oxygen debt [2].

In experimental models, tissue hypoperfusion has extensively been reported as a crucial pathophysiological event leading to tissue hypoxia and thereby organ failure $[3,4]$. Furthermore, hemorrhagic shock leads to a decrease of the fraction of perfused intestinal villi and thereby to an increase of the risk of villous ischemia [5]. Thereby it leads to intestinal damage with disruption of tight junction complexes and subsequent failure of the gut barrier [6-8].

This resulted in a translocation of luminal bacteria and leads to hyperinflammatory response and secondary complications like systemic inflammatory distress syndrome (SIRS), sepsis and multi-organ dysfunction syndrome (MODS) [9-13], which are main causes for late mortality of severely traumatized patients $[14,15]$.

This intestinal damage can be verified using the intestinal fatty acid-binding protein (I-FABP). FABPs are small intracellularly or within the plasma membrane localized proteins and are released into the extracellular space in their soluble extracellularly form early after cell or tissue damage [16]. Therefore, FABPs are used as plasma and urine markers for tissue-specific injuries [17]. The measurement of FABPs levels can be performed within hours by ELISA [18]. For heart-type FABP (H-FABP), a bedside test (qualitative rapid immunochemical point-of care-tests, POCT) is available, providing results within $15 \mathrm{~min}[19,20]$.

Among the nine organ-specific isoforms of FABP, the IFABP is solely present in enterocytes of the entire small intestine and partly in the colon and appears rapidly in the circulation after intestinal epithelial cell damage [21, 22]. IFABP has been studied as a biomarker for the diagnosis of necrotizing enterocolitis [23], the detection of mesenteric ischemia $[24,25]$ and strangulated mechanical small bowel obstruction [26]. In our own studies, we previously demonstrated that I-FABP is a significant marker for abdominal trauma [27-29]. Recently, a correlation between intestinal hypoperfusion and plasma I-FABP values was found [8].

For the present study, we hypothesized that I-FABP, as a marker for intestinal damage, could not only be a novel plasma marker in the early phase after trauma for the detection of abdominal injury but also for hemorrhagic shock, which leads to intestinal hypoperfusion and damage.

\section{Patients and methods}

\section{Study design}

This pilot study was performed at the University Hospital Frankfurt of the Goethe University with an
Institutional Ethics Committee approval (312/10, in accordance with the Declaration of Helsinki and reported following the Strengthening the Reporting of OBservational studies in Epidemiology, STROBE guidelines) [30]. Written informed consent was obtained from all enrolled subjects or their nominated legally authorized representatives on behalf of the participants in accordance with the ethical standards.

\section{Patients}

Severely injured patients with an Injury Severity Score (ISS) $\geq 16$ points [31] and $\geq 18$ years of age were included at admission to the emergency room (ER), in which sequential blood measurement over 3 days could be achieved. The study period was January 2010 to December 2016. Further inclusion criteria consisted of a history of acute blunt or penetrating trauma. Patients with burns, concomitant acute myocardial infarction, chronic diseases, and lethal injuries were excluded.

During the study period 26 patients retrospectively presented with hemorrhagic shock according to our definition outlined below and according to our inclusion and exclusion criteria: 8 patients without an abdominal injury ("HS noAbd") and 18 patients with an abdominal injury ("HS Abd").

Furthermore, 16 severely injured patients (ISS $\geq 25$ ) were coincidentally selected as control patients. These patients did not have any abdominal injury nor did they present in hemorrhagic shock ("noHS noAbd").

\section{Data collection}

Upon arrival to the ER vital parameters of all patients were recorded. Each injury was assigned an AIS score by a trained physician at hospital discharge and the ISS was calculated.

Abdominal injury was defined as an injury of the kidney, liver, spleen, pancreas, bladder, ureter and urethra, abdominal blood vessels, and intestine with an AIS abdomen $\geq 3$ points. The patient's characteristics were obtained from the patient's digital files.

For the present study, hemorrhagic shock was defined using the following criteria:

- Positive shock index (SI) $(\geq 1)$ prehospital or in the ER and

- Hemoglobin $(\mathrm{Hb})<10 \mathrm{~g} / \mathrm{dl}$ in the ER and

- Lactate value $\geq 4 \mathrm{mmol} / \mathrm{l}$ in the ER and

- The need of a massive transfusion $(\geq 10$ packed red blood cells (PRBC) within the first $24 \mathrm{~h}$.

\section{Sample collection}

Blood samples were obtained at admission to the ER (d0) and daily for 3 days (d1-d3) following trauma. Blood samples were collected in prechilled ethylenediaminetetraacetid 
acid tubes (BD Vacutainer, Bectom Dickinson Diagnostics, Aalst, Belgium) and kept on ice. Blood was centrifuged at $2000 \times g$ for $15 \mathrm{~min}$ at $4{ }^{\circ} \mathrm{C}$. The supernatant was stored at $80^{\circ} \mathrm{C}$ until the batch sample analysis. Blinded specimens were used for duplicate measurement of I-FABP levels. IFABP levels were determined by the laboratory of the Department of Trauma, Hand and Reconstructive Surgery at the Hospital of the Goethe University Frankfurt using a highly specific commercially available ELISA (Hycult Biotechnology, Uden, The Netherlands) according to manufacturer's instructions.

Blood sampling for the measurement of I-FABP was started in the year 2010. For the purpose of this study and as previously described, 26 patients with hemorrhagic shock were retrospectively identified and the I-FABP assays from the banked blood were performed in the year 2017. Furthermore, 16 severely injured patients (ISS $\geq 25$ ) without hemorrhagic shock and without abdominal injury were selected coincidentally as controls and I-FABP assays were run likewise.

\section{Data analysis}

The Kolmogoroff-Smirnoff-Lilleford's test showed that the plasma concentrations of I-FABP were not Gaussian distributed. Median I-FABP levels of the three groups ("noHS noAbd" vs. "HS noAbd" vs. "HS Abd") were compared using the Kruskal-Wallis test. In order to deal post hoc on non-parametric data, the Mann-Whitney $U$ test was applied and the Bonferroni adjustment of the $p$ value to correct for multiple comparisons was performed. Data are presented as the median and interquartile range (IQR) unless stated otherwise. A $p$ value of $<0.05$ was considered statistically significant.

Spearman's correlation coefficients were calculated to determine correlations between I-FABP levels and other variables.

Sensitivity, specificity, positive predictive value (PPV), and negative predictive value (NPV) were calculated and receiver operator characteristic curves (ROC) were generated to analyze the optimal cut-off level of I-FABP.

Bias 7.0 (Epsilon Verlag GbR 1989-2009, Germany) and GraphPad Prism 3.02 (GraphPad Software Inc. San Diego, CA) were used to perform the statistical analysis and computations.

\section{Results}

\section{Patient's characteristics}

Forty-two patients were enrolled in this study. Table 1 depicts the patients' demographic and injury characteristics. No statistically significant differences were found comparing the three groups regarding age, gender, ISS, hospital and intensive care unit (ICU) length of stay, and mortality. In the "noHS noAbd" group, a significantly higher AIS score of the head was noticed compared with the "HS Abd" group; however, no significant difference was found comparing both hemorrhagic shock groups. Furthermore, as per definition, the AIS abdomen score was significantly higher in the "HS Abd" group compared with both other patient groups $(p<0.05)$.

Table 2 outlines the physiologic characteristics of the three patient groups.

Statistically significant differences were found comparing the prehospital systolic blood pressure (SBP), the

Table 1 Summary of the patient's demographic and injury characteristics and the in-hospital outcome

\begin{tabular}{|c|c|c|c|c|c|}
\hline & $\begin{array}{l}\text { noHS noAbd } \\
(n=16)\end{array}$ & $\begin{array}{l}\text { HS noAbd } \\
(n=8)\end{array}$ & $\begin{array}{l}\text { HS Abd } \\
(n=18)\end{array}$ & $p$ value all groups & $\begin{array}{l}p \text { value } \\
\text { (HS noAbd vs. HS Abd.) }\end{array}$ \\
\hline Age & $48(30-56)$ & $44(27.8-48.5)$ & $44.5(38-62.8)$ & 0.76 & 0.64 \\
\hline Sex (male, $n, \%)$ & $12(75 \%)$ & $7(87.5 \%)$ & $15(83.3 \%)$ & 0.72 & 1.0 \\
\hline ISS & $34.5(32-41)$ & $34(33.8-35.8)$ & $42(36.5-50)$ & 0.13 & 0.19 \\
\hline \multicolumn{6}{|l|}{ AIS } \\
\hline Head & $4(3-5)$ & $0(0-4)$ & $0(0-3)$ & 0.001 & 0.57 \\
\hline Face & $0(0-3)$ & $1(0-2)$ & $0(0-1)$ & 0.46 & 0.36 \\
\hline Chest & $3(3-4)$ & $3(2-3)$ & $4(2-5)$ & 0.25 & 0.20 \\
\hline Abdominal & $0(0-0)$ & $0(0-0)$ & $4(3-4)$ & $<0.0001$ & $<0.0001$ \\
\hline Extremity & $3(2-4)$ & $5(3-5)$ & $3(2-4)$ & 0.16 & 0.18 \\
\hline Injury pattern ( $n$, blunt: penetrating) & 16: 0 & $6: 2$ & $16: 2$ & 0.14 & 0.56 \\
\hline ICU length of stay (days) & $16(11.5-23.8)$ & $17.5(4.5-31.8)$ & $21.5(10.5-29.0)$ & 0.68 & 0.74 \\
\hline Hospital length of stay (days) & $22(14.8-35.8)$ & $23.5(11.0-43.3)$ & $28.0(18.3-38.8)$ & 0.86 & 0.78 \\
\hline In-hospital Mortality $(n, \%)$ & $2(12.5 \%)$ & $2(33.3 \%)$ & $4(22.2 \%)$ & 0.69 & 1.0 \\
\hline
\end{tabular}

Values are reported as median (interquartile range, IQR) and as percentages

AIS, Abbreviated Injury Scale Score; HS Abd, hemorrhagic shock and abdominal injury; HS noAbd, hemorrhagic shock without abdominal injury; ICU, intensive care unit; ISS, Injury Severity Score; noHS noAbd, no hemorrhagic shock and no abdominal injury 
Table 2 Physiologic characteristics of the patient groups

\begin{tabular}{|c|c|c|c|c|c|}
\hline Physiologic characteristics & $\begin{array}{l}\text { noHS noAbd } \\
(n=16)\end{array}$ & $\begin{array}{l}\text { HS noAbd } \\
(n=8)\end{array}$ & $\begin{array}{l}\text { HS Abd } \\
(n=18)\end{array}$ & $\begin{array}{l}p \text { value all } \\
\text { groups }\end{array}$ & $\begin{array}{l}p \text { value } \\
\text { (HS noAbd vs. } \\
\text { HS Abd.) }\end{array}$ \\
\hline I-FABP (pg/ml, ER) & $844.4(530.0-1432.9)$ & $7292.3(1282.5-11,159.5)$ & $28,637.0(6372.4-55,550.0)$ & $<0.0001$ & 0.02 \\
\hline SBP (mm Hg, pre-hospital) & $130(95-151)$ & $115(88-129)$ & $70(68-90)$ & 0.0004 & 0.02 \\
\hline $\mathrm{SBP}(\mathrm{mm} \mathrm{Hg}, \mathrm{ER})$ & $105(86-120)$ & $100(78-113)$ & $71(61-106)$ & 0.11 & 0.40 \\
\hline heart rate ( $n /$ min, prehospital) & $91(80-110)$ & $120(110-121)$ & $116(100-130)$ & 0.05 & 0.73 \\
\hline heart rate (n/min, ER) & $101(90-110)$ & $115(101-123)$ & $120(88-132)$ & 0.29 & 0.98 \\
\hline shock index (prehospital) & $0.7(0.5-1.0)$ & $1.0(0.9-1.4)$ & $1.4(1.3-1.8)$ & 0.0002 & 0.05 \\
\hline shock index (ER) & $1.0(0.8-1.3)$ & $1.2(1.0-1.4)$ & $1.4(1.1-2.0)$ & 0.09 & 0.39 \\
\hline Fluid transfusion (ml, pre-hospital) & $1000(650-1000)$ & $1250(500-1750)$ & $1500(1000-1500)$ & 0.28 & 0.88 \\
\hline Fluid transfusion (ml, ER) & $1000(775-2250)$ & $3000(1937.5-6375)$ & $2000(1500-2500)$ & 0.02 & 0.08 \\
\hline PRBC transfusion within $24 \mathrm{~h}$ (Units) & $2(1-5.5)$ & $11.5(10.8-22.5)$ & $19(13-27.8)$ & $<0.0001$ & 0.18 \\
\hline PRBC transfusion total (Units) & $6(3.5-12.5)$ & $19.5(15.5-32.3)$ & $25.5(18-37.5)$ & $<0.0001$ & 0.44 \\
\hline FFP transfusion within $24 \mathrm{~h}$ (Units) & $0(0-3)$ & $10(5.8-17)$ & $15.5(11.3-19)$ & $<0.0001$ & 0.19 \\
\hline FFP transfusion total (Units) & $0(9-3)$ & $10(5.8-19)$ & $17.5(11.5-21.3$ & $<0.0001$ & 0.16 \\
\hline Hemoglobin (g/dl, ER) & $11.9(11.4-13.5)$ & $6.6(5.2-8.0)$ & $7.1(5.7-8.4)$ & $<0.0001$ & 0.49 \\
\hline $\mathrm{PTT}(\mathrm{s}, \mathrm{ER})$ & $28(24.5-30)$ & $48(38-51.5)$ & $38(29-45)$ & 0.002 & 0.1 \\
\hline INR (ER) & $1.1(1-1.3)$ & $1.3(1.2-1.8)$ & $1.3(1.1-1.5)$ & 0.06 & 0.32 \\
\hline Fibrinogen (mg/dl, ER) & $190.5(153-242.5)$ & $142(116.3-176)$ & $186.5(134-227.5)$ & 0.24 & 0.23 \\
\hline $\operatorname{PLT}$ count $\left(\times 10^{3} / \mu \mathrm{l}, \mathrm{ER}\right)$ & $186.5(155.8-256.8)$ & $94(51.3-137.8)$ & $178.5(113.3-206.8)$ & 0.03 & 0.03 \\
\hline Hemostatic therapy (done, n, \%) & $8(50 \%)$ & $8(100 \%)$ & $18(100 \%)$ & 0.0003 & 1.0 \\
\hline Leukocyte count (U/nl) & $10.8(9.5-13.5)$ & $9.9(8.8-11)$ & $8.6(6.7-10.8)$ & 0.14 & 0.47 \\
\hline Lactate (mmol/l, ER) & $2.4(1.9-3.9)$ & $7.4(6.4-10.6)$ & $8.5(6.7-9.2)$ & $<0.0001$ & 0.98 \\
\hline $\mathrm{pH}$ value & $7.3(7.2-7.4)$ & $7.4(7.1-7.4)$ & $7.2(7.1-7.2)$ & 0.03 & 0.26 \\
\hline Base deficit (mmol/l, ER) & $-5.1(-7.1--3.2)$ & $-7.2(-11.8--1.9)$ & $-10.1(-11.7--6.3)$ & 0.11 & 0.45 \\
\hline Temperature $\left({ }^{\circ} \mathrm{C}\right.$, ER) & $36(35.3-36.5)$ & $37(35.9-37.5)$ & $36.1(35.4-36.6)$ & 0.28 & 0.13 \\
\hline
\end{tabular}

Values are reported as median (interquartile range, IQR)

$E R$, emergency room; $F F P$, fresh frozen plasma; $H S A b d$, hemorrhagic shock with abdominal injury; $H S$ noAbd, hemorrhagic shock without abdominal injury; $I-F A B P$, intestinal fatty acid-binding protein; INR, international normalized ratio; noHS noAbd, no hemorrhagic shock and no abdominal injury; $P L T$, platelets; $P R B C$, packed red blood cells; $P T T$, partial thromboplastin time; $S B P$, systolic blood pressure

prehospital SI, the fluid resuscitation, transfusion of PRBC within $24 \mathrm{~h}$ and overall, transfusion of fresh frozen plasma (FFP) within $24 \mathrm{~h}$ and overall, hemoglobin value, partial thromboplastin time (PTT), platelet count, lactate, $\mathrm{pH}$ value, and need of hemostatic therapy $(p<0.05)$ between the three patient groups.

Comparing the "HS noAbd" group with the "HS Abd" group, a significant difference in the prehospital SBP and in the platelet counts was found.

\section{I-FABP level as a marker of severe abdominal injury and hemorrhagic shock}

The median concentrations of I-FABP at admission to the ER were significantly higher in the "HS Abd" group $(28,637.0 \mathrm{pg} / \mathrm{ml}[\mathrm{IQR}=6372.4-55,550.0])$ and in the "HS noAbd" group $(7292.3 \mathrm{pg} / \mathrm{ml} \quad[\mathrm{IQR}=1282.5-11,159.5])$ compared with the "noHS noAbd" group $(844.4 \mathrm{pg} / \mathrm{ml}$ [IQR $=530.0-1432.9], p<0.05$ ) (Fig. 1). Furthermore, the median I-FABP level was significantly higher in the "HS Abd" group compared with the "HS noAbd" group (Fig. 1, $p<0.05$ ).

\section{I-FABP in the 3-day posttraumatic course}

Figure 2 demonstrates the 3-day time-course of I-FABP for the three patient groups. In the ER, significantly higher I-FABP levels were found in "HS Abd" group compared with the other two patient groups. Likewise, I-FABP levels were statistically significantly higher in "HS noAbd" patients compared with the "noHS noAbd" group.

Following the first peak at admission (ER), I-FABP levels decreased in all three patient groups over the observed time course. On day 2 and 3, significantly higher I-FABP levels were noticed in the "HS Abd" patient group compared with the "noHS noAbd" group (Fig. 2, $p<0.05$ ). 


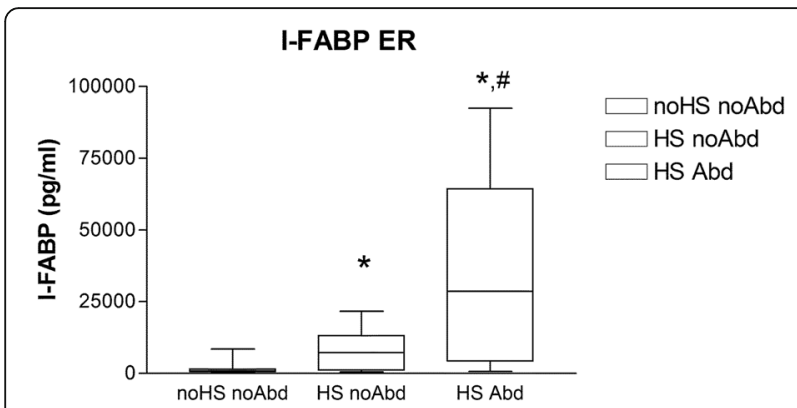

Fig. 1 I-FABP levels on admission to the emergency room. Median (interquartile range, IQR) intestinal fatty acid-binding protein (I-FABP) values in the three study groups based on the presence or absence of hemorrhagic shock and abdominal injury on admission to the emergency room. noHS noAbd ( $n=16)$; HS noAbd $(n=8)$; HS Abd ( $n=18) .{ }^{*}, p<0.05 \mathrm{HS}$ noAbd vs. noHs noAbd; HS Abd vs. noHS noAbd. \#, $p<0.05$ HS Abd vs. HS noAbd

\section{I-FABP correlates with clinical parameters for hemorrhagic shock}

The I-FABP levels at admission to the ER significantly correlated with the following clinical hemorrhagic shock parameters: base deficit (Fig. 3a), lactate value (Fig. 3b), prehospital and ER SBP (Fig. 3c), prehospital and ER SI (Fig. $3 \mathrm{~d}$ ), $\mathrm{Hb}$ value (Fig. $3 \mathrm{e}$ ), $\mathrm{pH}$ value (Fig. $3 \mathrm{f}$ ) and the amount of PRBC and FFP units transfused within the first $24 \mathrm{~h}$ and overall (Fig. $3 \mathrm{~g}+\mathrm{h}$, respectively).

Furthermore, statistically significant correlations between I-FABP levels at admission to the ER and leukocyte

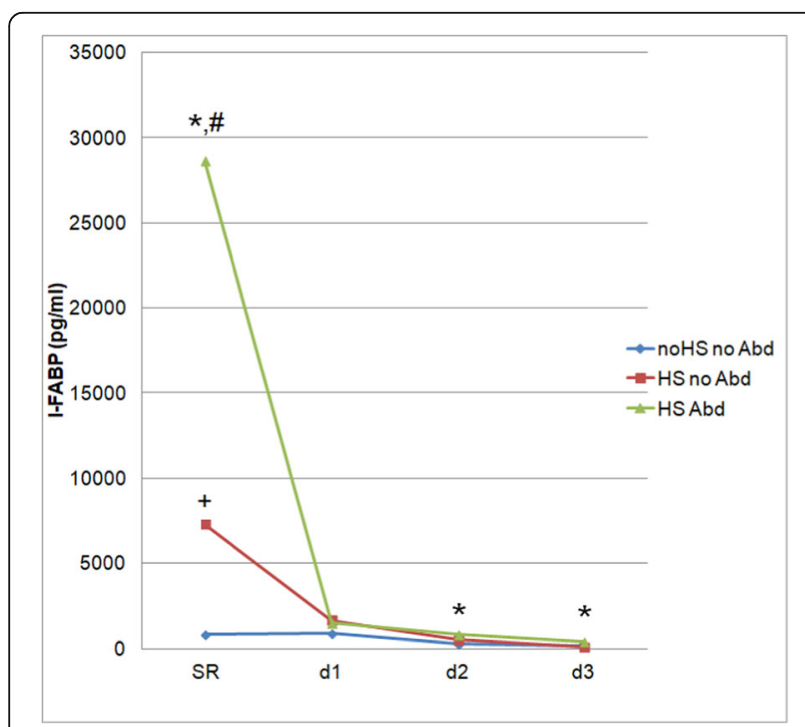

Fig. 2 Time course of I-FABP levels. Time course of median intestinal fatty acid-binding protein (I-FABP) levels $(\mathrm{pg} / \mathrm{ml})$ of all three patient groups based on the presence or absence of hemorrhagic shock and abdominal injury. ER, emergency room; HS Abd, hemorrhagic shock with abdominal injury; HS noAbd, hemorrhagic shock without abdominal injury; noHS noAbd, without hemorrhagic shock and without abdominal injury. *, $p<0.05$ HS Abd. vs. noHS noAbd; \#, $p<$ $0.05 \mathrm{HS}$ Abd. vs. HS noAbd;,$+ p<0.05 \mathrm{HS}$ noAbd vs. noHS noAbd counts, international normalized ratio (INR), and PTT levels were found.

There were no statistically significant correlations between I-FABP levels and fluid transfusion, platelet counts, fibrinogen, temperature, and ISS.

\section{ROC analysis for optimal cut-off level of I-FABP in hemorrhagic shock}

Receiver operating characteristic curve analysis shows an optimal cut-off level of I-FABP of $1761.9 \mathrm{pg} / \mathrm{ml}$ for detecting hemorrhagic shock, with $85 \%$ sensitivity and $81 \%$ specificity. The area under the curve (AUC) is $=0.89$ (Fig. 4).

The positive predictive value (PPV) and the negative predictive value (NPV) for I-FABP for detection of hemorrhagic shock were $88 \%$ and $76.5 \%$, respectively.

\section{Discussion}

One of the main causes for early mortality in severely traumatized patients is massive bleeding in almost 50\% [32]. Hemorrhagic shock leads to tissue hypoperfusion $[3,4]$ and intestinal damage $[6,8]$ consequently resulting in a translocation of bacteria, inflammatory response, and subsequently MODS $[9,12,13,33]$. These resulting secondary complications like SIRS, sepsis, and MODS [9-13] are main causes for late mortality of severely traumatized patients $[14,15]$.

The present study investigated the association between abdominal injury and I-FABP, as well as the association between hemorrhagic shock and I-FABP, as a marker for intestinal damage because of a reduced circulation and tissue hypoperfusion.

I-FABP is a primary marker for abdominal injury. In patients presenting with hemorrhagic shock to the ER, the presence of an abdominal injury significantly affected the I-FABP levels in this study. These results confirm our previously published results, showing that I-FABP is significantly increased in patients with abdominal injuries compared with patients without abdominal injuries $[27,29]$. In this respect, we have demonstrated earlier that I-FABP levels are increased in patients with a perforation or rupture of the small or large intestine [28]. The delayed diagnosis of an intestinal injury increases the risk of sepsis, MODS, acute respiratory distress syndrome, and mortality [34-37]. In fact, 3 of 4 patients with a delayed diagnosis had severe complications during the further clinical course [28].

The severity of trauma reveals a significant relationship with the I-FABP levels [38, 39]. In our own data, we have similarly reported a significant correlation between I-FABP levels and the overall severity of trauma, defined by using the ISS [29].

In the present study, however, the ISS was not statistically significant different between the different groups. 


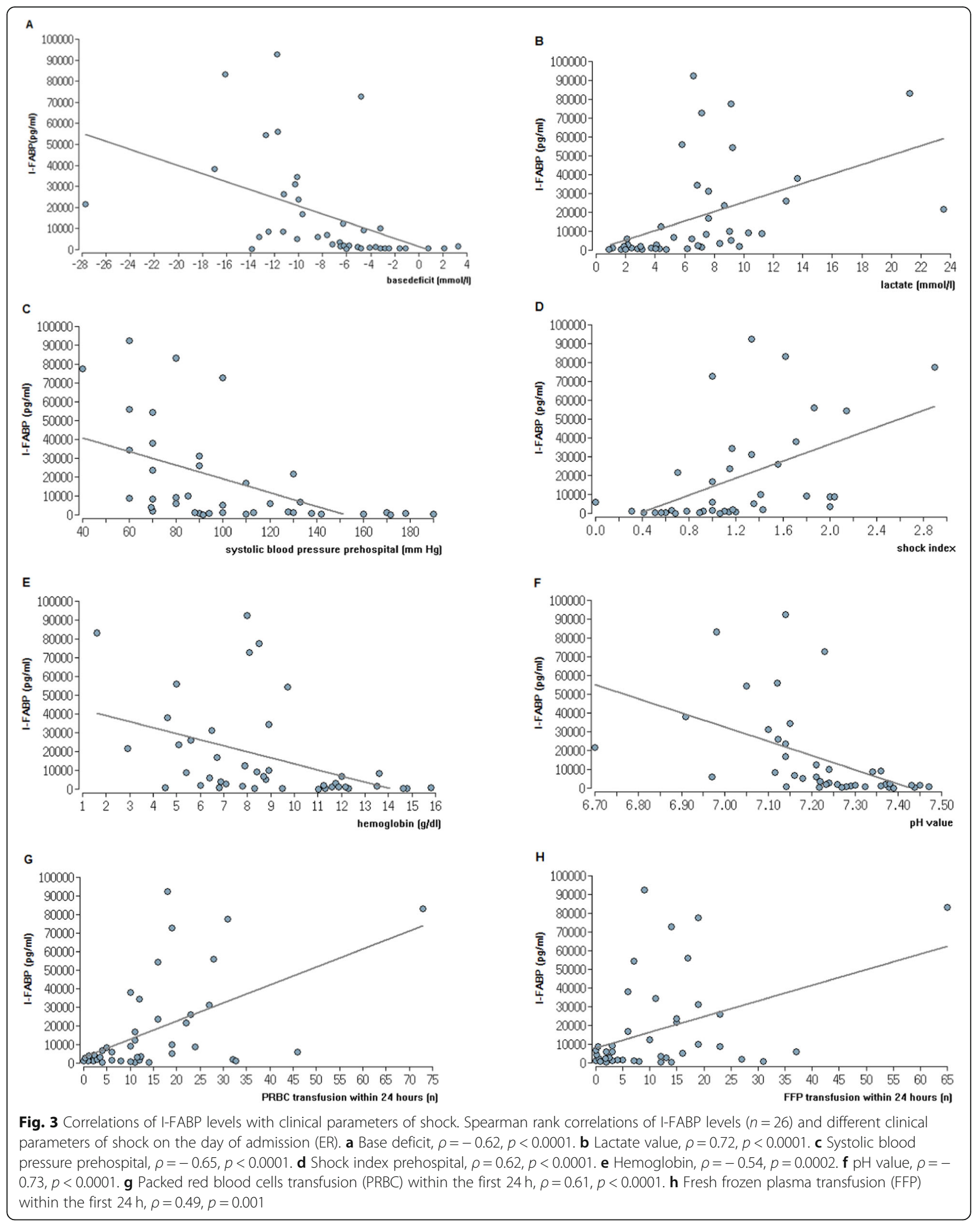




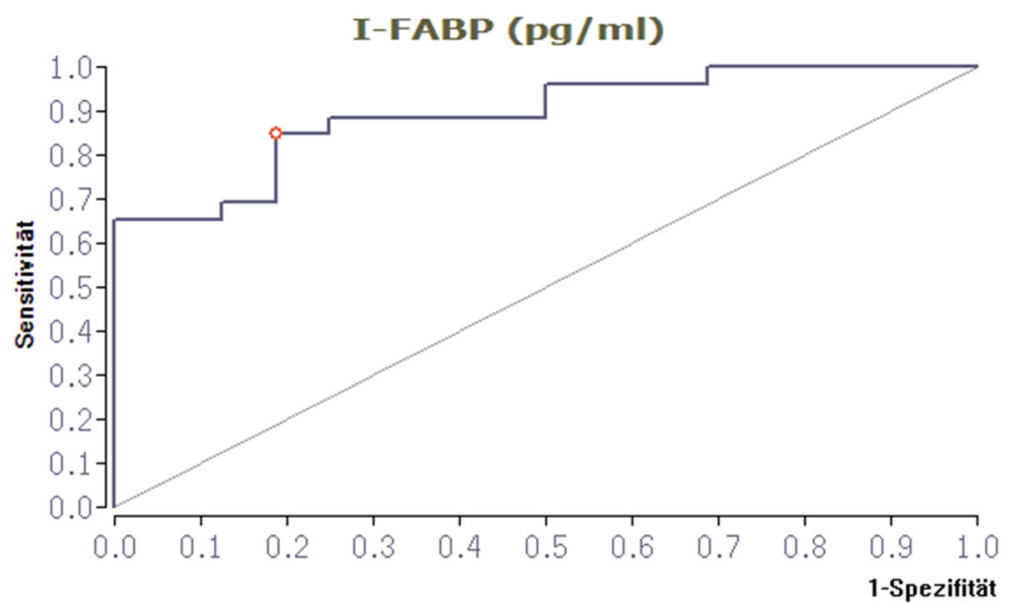

Fig. 4 Receiver operating curve of I-FABP for detection of hemorrhagic shock. Receiver operating characteristic curve showing the optimal cut-off for I-FABP levels $(1761.9 \mathrm{pg} / \mathrm{ml})$ in predicting the presence or the absence of hemorrhagic shock with $85 \%$ sensitivity and $81 \%$ specificity. I-FABP, intestinal fatty acid-binding protein

This excluded a relevant impact of the overall injury severity on the measured I-FABP levels. Additionally, we have not observed significant differences concerning the specific patient characteristics between the three patient groups in this current study.

The new finding of the data presented is that patients with hemorrhagic shock exhibited a significantly higher I-FABP level at admission to the ER as compared with those patients without hypovolemia. Most importantly, this difference was independent from the presence or absence of an abdominal injury. We could calculate an optimal cut-off level for I-FABP for detection of a hemorrhagic shock of $1761.9 \mathrm{pg} / \mathrm{ml}$ with a sensitivity of $85 \%$ and a specificity of 81 . This shows the potential usefulness of I-FABP as an early marker for hemorrhagic shock or-intestinal hypoperfusion by that. The detection of intestinal hypoperfusion and thereby resulting intestinal damage is still an unsolved problem in the clinical setting, due to the lack of direct access and of specific markers [40-42]. From all, I-FABP is the most promising biomarker for the detection of intestinal hypoperfusion [41].

To the best of our knowledge, this is the first study presenting a profound evidence for a significant correlation between I-FABP levels and hemorrhagic shock in trauma patients. In previously published studies, correlations between I-FABP and hypoperfusion of the intestine were found [8]. Furthermore, other studies showed increased I-FABP levels in patients with low $\mathrm{Hb}$ values, low mean arterial pressure (MAP), and elevated SI, and were likewise related to the severity of trauma [29, 38, 39]. However, in particular due to compensatory mechanisms of the human body, the two clinical parameters, low blood pressure and SI, are unreliable parameters in determining the presence of hemorrhagic shock. It has been shown that none of these parameters is adequately sensitive or specific to detect early hemorrhage [43]. Serum markers like lactate or base deficit determine tissue hypoperfusion and global tissue acidosis, respectively, and are the most commonly used serum markers for hemorrhagic shock [44-48]. These two parameters likewise correlated with I-FABP in the present study. Additionally, correlations were found with routinely used and clinically relevant parameters such as the $\mathrm{Hb}$ value and SBP on admission, amount of PRBC and FFP transfused, SI, and $\mathrm{pH}$ value. Also, INR and PTT, both markers of coagulation disorders, significantly correlated with I-FABP levels on admission. Overall, our results suggest that I-FABP could serve as a novel marker for the detection of hemorrhagic shock.

The present analysis has several limitations, most importantly the limited number of patients enrolled. Future studies should involve larger cohorts of patients and controls to confirm our findings and to analyze sensitivity and specificity of I-FABP levels to detect hemorrhagic shock, abdominal injury, and injuries to specific abdominal organs in particular. In particular, it might be relevant to evaluate whether I-FABP is an independently early-detectable and sensitive marker of hemorrhagic shock. Such a marker would allow early improved or maybe even a monitoring of shock therapy.

Likewise, since we observed an early decrease of the initially elevated I-FABP levels to normal values, the usefulness of FABP assays in the clinical setting needs to be evaluated in a prospective setting.

Furthermore, no bedside-test for a rapid measurement of I-FABP currently exists for these situations. The IFABP testing is performed using an ELISA test, taking 2 to $4 \mathrm{~h}$ for measurement and therefore limiting its clinical relevance in the acute setting up to now. Otherwise, the 
measurement of I-FABP by using ELISA is easy and the cost is only 13 Euros per patient. Introducing I-FABP on clinical routine would stimulate the development of a point of care approach, as it was already developed for H-FABP, with a bedside test with available results within $15 \mathrm{~min}$ for acute coronary syndrome or myocardial infarction [19].

\section{Conclusion}

In conclusion, I-FABP levels not only identify patients with abdominal trauma but also allow the detection of hemorrhagic shock, most likely due to the hypoperfusion of the intestine in this situation. Thus, I-FABP is a useful and promising early marker for the detection of abdominal injury and even in the absence of an abdominal injury it is a marker of intestinal damage and hemorrhagic shock.

\section{Abbreviations}

AUC: Area under the curve; ER: Emergency Room; FFP: Fresh frozen plasma; $\mathrm{Hb}$ : Hemoglobin; H-FABP: Heart-type fatty acid binding protein; HS Abd: Patients with hemorrhagic shock and abdominal injury; HS noAbd: Patients with hemorrhagic shock and without abdominal injury; ICU: Intensive care unit; I-FABP: Intestinal fatty acid binding protein; INR: International normalized ratio; IQR: Interquartile range; ISS: Injury Severity Score; MAP: Mean arterial pressure; MODS: Multiple organ dysfunction syndrome; noHS noAbd: Patients without hemorrhagic shock and without abdominal injury; NPV: Negative predictive value; PPV: Positive predictive value; PRBC: Packed red blood cells; PTT: Partial thromboplastin time; ROC: Receiver operator characteristic curves; SBP: Systolic blood pressure; SI: Shock index; SIRS: Systemic inflammatory distress syndrome

\section{Acknowledgements}

Not applicable.

\section{Authors' contributions}

$\mathrm{MV}, \mathrm{TL}, \mathrm{BR}$, and IM designed the study, developed the methodology, performed the analysis, and wrote the manuscript. All authors read and approved the final manuscript.

\section{Funding}

Funding information is not available.

\section{Availability of data and materials}

The datasets during and/or analyzed during the current study available from the corresponding author on reasonable request.

\section{Ethics approval and consent to participate}

Institutional Ethics Committee approval (312/10, in accordance with the Declaration of Helsinki and reported following the Strengthening the Reporting of OBservational studies in Epidemiology, STROBE guidelines). Written informed consent was obtained from all enrolled subjects or their nominated legally authorized representatives on behalf of the participants in accordance with the ethical standards.

\section{Consent for publication}

Not applicable.

\section{Competing interests}

The authors declare that they have no competing interests.
Received: 14 August 2019 Accepted: 26 September 2019

Published online: 21 November 2019

\section{References}

1. Rossaint R, Bouillon B, Cerny V, Coats TJ, Duranteau J, Fernández-Mondéjar E, Hunt BJ, Komadina R, Nardi G, Neugebauer E, Ozier Y, Riddez L, Schultz A, Stahel PF, Vincent J-L, Spahn DR. Management of bleeding following major trauma: an updated European guideline. Crit Care. 2010;14:R52.

2. Baron BJ, Scalea TM. Acute blood loss. Emerg Med Clin North Am. 1996;14:35-55.

3. Dunham CM, Siegel JH, Weireter L, Fabian M, Goodarzi S, Guadalupi P, Gettings L, Linberg SE, Vary TC. Oxygen debt and metabolic acidemia as quantitative predictors of mortality and the severity of the ischemic insult in hemorrhagic shock. Crit Care Med. 1991;19:231-43.

4. Rixen D, Raum M, Holzgraefe B, Sauerland S, Nagelschmidt M, Neugebauer EA. A pig hemorrhagic shock model: oxygen debt and metabolic acidemia as indicators of severity. Shock. 2001;16:239-44.

5. Harrois A, Baudry N, Huet O, Kato H, Lohez M, Ziol M, Duranteau J, Vicaut E. Synergistic deleterious effect of hypoxemia and hypovolemia on microcirculation in intestinal villi*. Crit Care Med. 2013;41:e376-84.

6. Moore FA. The role of the gastrointestinal tract in postinjury multiple organ failure. Am J Surg. 2000;178:449-53.

7. Thuijls G, de Haan J-J, Derikx JPM, Daissormont I, Hadfoune M, Heineman E, Buurman WA. Intestinal cytoskeleton degradation precedes tight junction loss following hemorrhagic shock. Shock. 2008;31:164-9.

8. Derikx JPM, Poeze M, van Bijnen AA, Buurman WA, Heineman E. Evidence for intestinal and liver epithelial cell injury in the early phase of sepsis. Shock. 2007;28:544-8.

9. Deitch EA, Xu D, Kaise VL. Role of the gut in the development of injury- and shock induced SIRS and MODS: the gut-lymph hypothesis, a review. Front Biosci. 2006;11:520-8.

10. Berg RD. Bacterial translocation from the gastrointestinal tract. Adv Exp Med Biol. 2000;473:11-30.

11. Baumgart DC, Dignass AU. Intestinal barrier function. Curr Opin Clin Nutr Metab Care. 2002;5:685-94.

12. Fink MP, Delude RL. Epithelial barrier dysfunction: a unifying theme to explain the pathogenesis of multiple organ dysfunction at the cellular level. Crit Care Clin. 2005;21:177-96.

13. Van Leeuwen PA, Boermeester MA, Houdijk AP, Ferwerda CC, Cuesta MA, Meyer S, Wesdorp RI. Clinical significance of translocation. Gut. 1994;35:528-34

14. Waydhas C, Nast-Kolb D, Jochum M, Trupka A, Lenk S, Fritz H, Duswald KH, Schweiberer L. Inflammatory mediators, infection, sepsis, and multiple organ failure after severe trauma. Arch Surg. 1992;127:460-7.

15. Keel M, Trentz O. Pathophysiology of polytrauma. Injury. 2005;36:691-709.

16. Glatz JF, van der Vusse GJ. Cellular fatty acid-binding proteins: their function and physiological significance. Prog Lipid Res. 1996;35:243-82.

17. Pelsers MMAL, Hermens WT, Glatz JFC. Fatty acid-binding proteins as plasma markers of tissue injury. Clin Chim Acta. 2005;352:15-35.

18. Chan CPY, Wan TSM, Watkins KL, Pelsers MMAL, Van der Voort D, Tang FPW, Lam KHK, Mill J, Yuan Y, Lehmann M, Hempel A, Sanderson JE, Glatz JFC, Renneberg R. Rapid analysis of fatty acid-binding proteins with immunosensors and immunotests for early monitoring of tissue injury. Biosens Bioelectron. 2004;20:2566-80.

19. Kokorin VA, Arefiev MN, Levchouk NN, Gordeev IG. Diagnostic value of qualitative bedside heart-type fatty acid-binding protein tests compared with cardiac troponin assays in patients with suspected acute coronary syndrome. Pol Arch Intern Med. 2018;128:623-5.

20. Sonmez BM, Ozturk D, Yilmaz F, Altinbilek E, Kavalci C, Durdu T, Hakbilir O, Turhan T, Ongar M. Bedside heart type fatty acid binding protein (H-FABP): is an early predictive marker of cardiac syncope. J Pak Med Assoc. 2015;65:1156-60.

21. Lieberman JM, Sacchettini J, Marks C, Marks WH. Human intestinal fatty acid binding protein: report of an assay with studies in normal volunteers and intestinal ischemia. Surgery. 1997;121:335-42.

22. Pelsers MMAL, Namiot Z, Kisielewski W, Namiot A, Januszkiewicz M, Hermens WT, Glatz JFC. Intestinal-type and liver-type fatty acid-binding protein in the intestine. Tissue distribution and clinical utility. Clin Biochem. 2003;36:529-35.

23. Heida FH, Hulscher JBF, Schurink M, Timmer A, Kooi EMW, Bos AF, Bruggink JLM, Kasper DC, Pones M, Benkoe T. Intestinal fatty acid-binding protein levels in necrotizing enterocolitis correlate with extent of necrotic bowel: results from a multicenter study. J Pediatr Surg. 2014;50:1115-8. 
24. Kanda T, Tsukahara A, Ueki K, Sakai Y, Tani T, Nishimura A, Yamazaki T, Tamiya Y, Tada T, Hirota M, Hasegawa J, Funaoka H, Fujii H, Hatakeyama K. Diagnosis of ischemic small bowel disease by measurement of serum intestinal fatty acid-binding protein in patients with acute abdomen: a multicenter, observer-blinded validation study. J Gastroenterol. 2011;46:492-500.

25. Shi H, Wu B, Wan J, Liu W, Su B. The role of serum intestinal fatty acid binding protein levels and D-lactate levels in the diagnosis of acute intestinal ischemia. Clin Res Hepatol Gastroenterol. 2015;39:373-8.

26. Cronk DR, Houseworth TP, Cuadrado DG, Herbert GS, McNutt PM, Azarow KS. Intestinal fatty acid binding protein (I-FABP) for the detection of strangulated mechanical small bowel obstruction. Curr Surg. 2006;63:322-5.

27. Voth M, Holzberger S, Auner B, Henrich D, Marzi I, Relja B. I-FABP and L-FABP are early markers for abdominal injury with limited prognostic value for secondary organ failures in the post-traumatic course. Clin Chem Lab Med. 2014:53:771-80

28. Voth M, Duchene M, Auner B, Lustenberger T, Relja B, Marzi I. I-FABP is a novel marker for the detection of intestinal injury in severely injured trauma patients. World J Surg. 2017;41:3120-7.

29. Relja B, Szermutzky M, Henrich D, Maier M, de Haan J-J, Lubbers T, Buurman WA, Marzi I. Intestinal-FABP and liver-FABP: novel markers for severe abdominal injury. Acad Emerg Med. 2010;17:729-35.

30. Elm von E, Altman DG, Egger M, Pocock SJ, Gøtzsche PC, Vandenbroucke JP. The strengthening the reporting of Observational Studies in Epidemiology (STROBE) statement: guidelines for reporting observational studies. Int J Surg. 2014;12:1495-9.

31. Baker SP, O'Neill B, Haddon W, Long WB. The injury severity score: a method for describing patients with multiple injuries and evaluating emergency care. J Trauma. 1974;14:187-96.

32. Nast-Kolb D, Waydhas C, Kastl S, Duswald KH, Schweiberer L. The role of an abdominal injury in follow-up of polytrauma patients. Chirurg. 1993;64:552-9.

33. Clark JA, Coopersmith CM. Intestinal crosstalk: a new paradigm for understanding the gut as the "motor" of critical illness. Shock. 2007;28:384-93.

34. Malinoski DJ, Patel MS, Yakar DO, Green D, Qureshi F, Inaba K, Brown CVR, Salim A. A diagnostic delay of 5 hours increases the risk of death after blunt hollow viscus injury. J Trauma. 2010;69:84-7.

35. Niederee MJ, Byrnes MC, Helmer SD, Smith RS. Delay in diagnosis of hollow viscus injuries: effect on outcome. Am Surg. 2003;69(4):293-9.

36. Shebrain S, Zelada J, Lipsky AM, Putnam B. Mesenteric injuries after blunt abdominal trauma: delay in diagnosis and increased morbidity. Am Surg. 2006:72:955-61.

37. Sung CK, Kim KH. Missed injuries in abdominal trauma. J Trauma. 1996;41:276-82.

38. Timmermans K, Sir Ö, Kox M, Vaneker M, de Jong C, Gerretsen J, Edwards M, Scheffer GJ, Pickkers P. Circulating iFABP levels as a marker of intestinal damage in trauma patients. Shock. 2014;43:117-20.

39. de Haan JJ, Lubbers T, Derikx JP, Relja B, Henrich D, Greve J-W, Marzi I, Buurman WA. Rapid development of intestinal cell damage following severe trauma: a prospective observational cohort study. Crit Care. 2009;13:R86.

40. Derikx JPM, Schellekens DHSM, Acosta S. Serological markers for human intestinal ischemia: a systematic review. Best Pract Res Clin Gastroenterol. 2017:31:69-74.

41. Powell A, Armstrong P. Plasma biomarkers for early diagnosis of acute intestinal ischemia. Semin Vasc Surg. 2015;27:170-5.

42. Clair DG, Beach JM. Mesenteric ischemia. N Engl J Med. 2016;374:959-68.

43. Surgeons CACO: American College of Surgeons Committee on Trauma: Hemorrhagic Shock. In: American College of Surgeons Committee on Trauma. Advanced Trauma Life Support Student Course Manual Tenth Edition. Chicago: 2018. p. 48-54.

44. Davis JW, Shackford SR, Mackersie RC, Hoyt DB. Base deficit as a guide to volume resuscitation. J Trauma. 1988;28:1464-7.

45. Huckabee WE. Abnormal resting blood lactate. Am J Med. 1961;30:840

46. Davis JW, Shackford SR, Holbrook TL. Base deficit as a sensitive indicator of compensated shock and tissue oxygen utilization. Surg Gynecol Obstet. 1991:173:473-6.

47. Davis JW, Parks SN, Kaups KL, Gladen HE, O'Donnell-Nicol S. Admission base deficit predicts transfusion requirements and risk of complications. J Trauma. 1996:41:769-74.

48. Broder $\mathrm{G}$, Weil $\mathrm{MH}$. Excess lactate: an index of reversibility of shock in human patients. Science. 1964:143(3613):1457-9.

\section{Publisher's Note}

Springer Nature remains neutral with regard to jurisdictional claims in published maps and institutional affiliations.

\section{Ready to submit your research? Choose BMC and benefit from:}

- fast, convenient online submission

- thorough peer review by experienced researchers in your field

- rapid publication on acceptance

- support for research data, including large and complex data types

- gold Open Access which fosters wider collaboration and increased citations

- maximum visibility for your research: over $100 \mathrm{M}$ website views per year

At BMC, research is always in progress.

Learn more biomedcentral.com/submissions 